\section{BMJ Open Sport \& Exercise Medicine}

\title{
Managing the health of the eSport athlete: an integrated health management model
}

\author{
Joanne DiFrancisco-Donoghue, ${ }^{1,2}$ Jerry Balentine, ${ }^{3}$ Gordon Schmidt, ${ }^{4}$ \\ Hallie Zwibel ${ }^{2,5}$
}

\section{To cite:}

DiFrancisco-Donoghue $J$, Balentine J, Schmidt G, et al. Managing the health of the eSport athlete: an integrated health management model. BMJ Open Sport \& Exercise Medicine 2019;5:e000467. doi:10.1136/ bmjsem-2018-000467

Accepted 18 December 2018

Check for updates

C) Author(s) (or their employer(s)) 2019. Re-use permitted under CC BY-NC. No commercial re-use. See rights and permissions. Published by BMJ.

${ }^{1}$ Department of Osteopathic Medicine, New York Institute of Technology College of Osteopathic Medicine (NYITCOM), New York City, New York, USA

${ }^{2}$ Center for Sports Medicine NYIT-COM, New York City, New York, USA

${ }^{3}$ Office of the Vice President NYIT-COM, New York City, New York, USA

${ }^{4}$ Office of the Dean NYIT-School of Health Professions, New York City, New York, USA

${ }^{5}$ Department of Family Medicine NYIT-COM, New York City, New York, USA

Correspondence to Dr Joanne DiFranciscoDonoghue; jdonoghu@nyit.edu

\section{ABSTRACT}

Objectives eSport is a form of electronic gaming, also known as professional or competitive video gaming, and is growing at a rapid pace worldwide. Over 50 US colleges have established varsity gaming teams over the past three years; some colleges offer eSport scholarships as they do for traditional sports. There is little objective research on the health habits of these players who are often placed under the direction of the athletics department on college campuses, and there is currently no health management model on how to treat these new athletes.

Methods Anonymous electronic surveys were sent to 65 collegiate eSport players from nine universities across the USA and Canada inquiring about gaming and lifestyle habits, and musculoskeletal complaints due to eSport competition.

Results Players practiced between 3 and 10 hours per day. The most frequently reported complaint was eye fatigue (56\%), followed by neck and back pain (42\%). eSport athletes reported wrist pain (36\%) and hand pain $(32 \%)$. Forty per cent of participants do not participate in any form of physical exercise. Among the players surveyed, only $2 \%$ had sought medical attention.

Conclusion eSport players, just like athletes in traditional sports, are susceptible to overuse injuries. The most common complaint was eye fatigue, followed by neck and back pain. This study shows eSport athletes are also prone to wrist and hand pain. This paper proposes a health management model that offers a comprehensive medical team approach to prevent and treat eSport athletes.

\section{INTRODUCTION}

Hundreds of millions of players are engaged daily in virtual and competitive electronic gaming-eSport. ${ }^{1}$ Whether it is playing these games or just being a fan, eSports enthusiasts have proliferated throughout the world. According to Newzoo, a market tracking company, 427 million people will be watching eSports by 2019 and will reach a global audience of 1.1 billion by 2021. ${ }^{1}$ Player earnings from sponsorships and prizes exceed $\$ 1.5$ billion. ${ }^{2}$ In recent months, competitive gaming (eSport) has received a large amount of social media and public attention. Ninety per cent of children in the USA play electronic
What are the new findings?

eSport has grown rapidly on a collegiate level, and currently $>50$ colleges in the USA have competitive teams.

- Forty per cent did not participate in any form of physical activity.

- The time sitting in front of a computer for a collegiate eSport player ranges from 5.5 to 10 hours daily.

- The most common ailment from eSport players was eye fatigue, followed by neck, back, wrist and hand pain.

How might it impact on clinical practice in the near future?

We call for clinical practice guidelines for eSport players.

- We recommend sports physicians and other health professionals better understand the medical needs of these athletes; eSports should be included in the clinical sports medicine curriculum.

video games on a regular basis. ${ }^{3}$ The IOC on 28 October 2017 in Lausanne, Switzerland, has accepted that eSport is a sporting activity. ${ }^{4}$ Viewership is so high for certain games (such as League of Legends) that it has bypassed the Major League World series. ${ }^{56}$ These competitions are aired on YouTube or on streaming sites. The most widely known is 'Twitch.com' which accounts for $>40 \%$ of eSport streaming volume. Twitch was purchased by Amazon in 2014 for $\$ 970$ million.

Colleges, universities, and high schools are adding eSport teams at a rapid pace. It is appealing for a school because it attracts a different type of student than the prototypical athlete image. In South Korea, universities classify eSport competitors as traditional athletes. ${ }^{7}$ In the US, over 50 colleges have varsity eSport teams under the National Association of Collegiate eSports (NACE). ${ }^{8}$ Twenty-two colleges in the US currently offer scholarships for gaming.

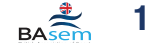


High schools across the United States have launched a competitive varsity season in the fall of $2018 .{ }^{9}$ Undergraduate programme have been created and offered in the industry of eSport. The NCAA is currently investigating eSport as a recognised sport. In 2018, the National Basketball Association developed NBA's 2K League. This consists of a group of 17 franchises affiliated with NBA teams that play electronic basketball. This league gets aired on ESPN's sport channel and has drafts similar to professional basketball.

There is, however, little known about the physical and mental health demands and injury management of eSport players. This new sport requires the support of health professionals who understand social or addictive behaviours, changes in academic or work performance, and chronic eSport participatory injuries such as wrist or hand problems, eye strain and postural assessments.

Our aim was to report the common health issues that occur in competitive gaming and outline a healthcare model for institutions to help create protocols to prevent and treat common health concerns in eSport athletes.

\section{A changing role for coaches and healthcare practitioners in sports medicine and rehabilitation}

eSport has received much controversy from critics as a traditional sport due to its lack of physicality. Regardless of this debate, the eSport team are the 'new athletes' on campus and they should be held to the same standards of other athletes. These teams have uniforms, coaches; they practice together and compete regularly. However, they do not have the sport administration behind them of traditional sports teams. When we think of an eSport player, we do not typically think of a physician's clearance to participate in a sedentary activity with little chance of injury. Quite contrary to that belief, these athletes suffer health concerns and chronic overuse injuries. ${ }^{10}$ It is common for professional eSport athletes to suffer career-ending injuries. The most common injury is wrist and hand injuries. ${ }^{10}$ Alarmingly, in 2013 pro StarCraft 2 Player Geoff 'Incontrol' Robinson suffered from a blood clot in his knee. This clot is also called a deep vein thrombosis (DVT) which is common when individuals sit for long periods of time. ${ }^{1011}$ If ignored, DVT can travel to the lungs and cause a pulmonary embolism which is life threatening. ${ }^{11}$ The common concerns and injuries that are seen in eSport athletes are not the typical injuries seen in traditional student athletes and many health professionals and trainers may not know what type of injuries to look for.

eSport athletes at a collegiate level have talents that exceed the skills of the average recreational virtual gaming players. The manual dexterity that is needed to perform the actions required to compete has a direct impact on the athlete's performance. ${ }^{12}$ These games require thinking skills and reaction times faster than their competitor. ${ }^{12}$ Whereas novice players average approximately 50 action moves per minute, higher level athletes make 10 moves per second or 500-600 action moves per minute. $^{13}$

In order to succeed at gaming on a competitive level, athletes are required to play for many hours a day. College and school teams can practice together for 3-4 hours a day, with many of them going home to continue practising their game. In many cases, they practice in a less than ideal environment with improper posture, lighting and time awareness.

eSport requires players to have their eyes fixed on a computer screen with excessive exposure to light-emitting diodes (LEDs). LEDs are used to provide illumination in computers, smartphones, tablets and televisions. LEDs have a broad spectrum of light. They appear white, but these LEDs have a peak emission in the blue light range of (400-490 nm). ${ }^{14}$ Recent research has demonstrated that excessive exposure to this blue-light spectrum can create retinal and photoreceptor damage. ${ }^{14} 15$ Excessive exposure can also impact the natural circadian rhythm. ${ }^{14} 15$ Melatonin is a hormone synthesised in our bodies. It is an important marker of the natural circadian clock. Typically, melatonin is lowest during awake hours during the day and then rises at night before sleep. Excessive exposure to LED lights, seen in computer screens, can alter melatonin levels. ${ }^{16}$ Players often need to take breaks to refocus their eyes.

There are very little data on lifestyle habits and common complaints from eSport players.

This paper presents results of a survey that characterise lifestyle habits of collegiate eSport players and a proposed healthcare model for eSport athletes.

\section{METHODS}

Sixty-five collegiate varsity eSport players between the ages of 18-22 years were surveyed from eight different universities in the USA. Data were collected using an anonymous, self-reported electronic questionnaire. These players were from various geographic areas that included the Northeast, the West coast, the South East and the Midwest. The data highlight important lifestyle behaviours and the importance of establishing appropriate services to manage eSport player's health. This questionnaire was developed by a collaborative effort of the eSport players on the New York Institute of Technology campus based on common injuries they have encountered in the past.

\section{RESULTS}

Findings indicate that the average eSport player practices between 5.5 and up to 10 hours a day prior to competitions. Figure 1 depicts four medical conditions associated with these eSport players. Fifteen per cent reported 3 hours or more of sitting and playing without standing to take a break. Forty per cent of the players reported they do not participate in any kind of physical activity. The largest complaint reported was eye fatigue, back and neck pain was the second largest complaint, followed by wrist and hand pain. The injuries seen in eSport athletes 
PLAYERS WHO REPORTED HAND PAIN

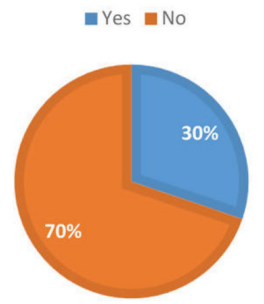

PLAYERS WHO REPORTED BACK OR NECK PAIN

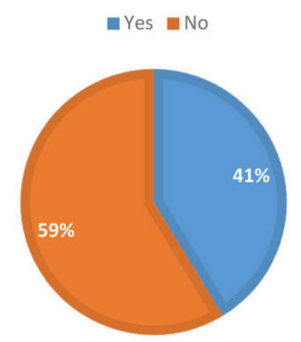

PLAYERS WHO REPORTED EYE FATIGUE

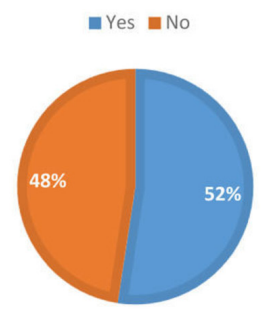

PLAYERS WHO HAVE REPORTED WRIST PAIN

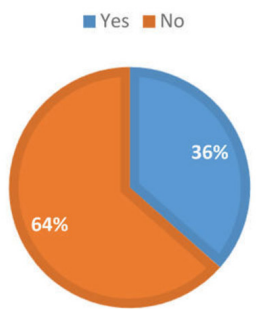

Figure 1 Reported pain from eSport players surveyed.

are similar to injuries seen in sedentary office personnel, as opposed to complaints commonly seen by sports medicine specialists. ${ }^{17}$ Of the athletes surveyed who suffered from an ailment, only $2 \%$ sought medical attention.

\section{DISCUSSION}

The injuries seen in eSports are similar to conditions seen in sedentary desk jobs with the incorporation of intense dexterous actions. Exercise deficit disorder is a term used to describe reduced levels of physical activity that are not compliant with current public health recommendations. ${ }^{18}$ It has been proposed that physicians diagnose $<60$ min a day of physical activity in youth as 'Exercise-Deficit Disorder'. ${ }^{19}$ The current survey demonstrated that $>40 \%$ of these players have $<60 \mathrm{~min}$ of activity a day. Although a player might fulfil the recommended exercise requirements by American College of Sports Medicine or the Center of Disease Control, sitting for prolonged periods of time using small muscle groups will eventually result in an injury. The psychosocial components seen in eSport can include addictive behaviour, personal hygiene issues, social anxiety and sleep disturbances. It is associated with mental and health disorders as well. In 2018, WHO has included gaming in its 11th Revision of the International Classification of Diseases stating that gaming disorder is "characterized by impaired control over gaming, increasing priority given to gaming over other activities to the extent that gaming takes precedence over other interests and daily activities, and continuation or escalation of gaming despite the occurrence of negative consequences'. ${ }^{\circ}$

Sports medicine for athletes who play contact sports or who require physical training is challenging. Most collegiate athletes have specific training programmes targeting their sport. These plans include exercise to prevent injuries, improve health and performance. When an athlete suffers an injury, there are protocols in place to evaluate, treat and guidelines on return to play. Many of these decisions are from several health professionals, and communication between these disciplines is essential. This structure can affect a team, and it can also affect the long-term health of a player.

\section{Integrating health professionals for the eSport athlete}

Working with any sport team at any level requires a relationship with the players and the coach. A plan of services should include baseline testing, clinical evaluations and services as well as physical and mental health assessments. This can help with academic performance and social behaviours and should be presented in a way that does not bombard the players with too many evaluations or tests but offers a time frame and an explanation of how these tests can benefit them.

The health management team of eSport players faces a great deal of health-related challenges. The current NYIT eSport model follows the traditional medical model whereby the physician (usually a sport physician) is the primary contact and 'gatekeeper'. However, the first point of contact with a healthcare professional may also be a physical therapist, team doctor, general practitioner, sports physician or psychologist. This model is based on each individual discipline operating in its own specialty with effective communication to each team member. The team has two focuses: integrating health management and understanding the demands needed to improve eSport skills.

Traditionally, the head coach has the performance expertise to manage performance, game plan and sport-specific strength and conditioning goals. In this specific model, there is a balance of the eSport coach to help health professionals understand the minimal training required to compete at the expected level of each player. In this alternative model, the health professionals will have to find a delicate balance of incorporating expertise in physical and mental well-being interspersed in this training protocol. The following section introduces a structured medical team model for a varsity eSport team that can balance health management while optimising gaming performance. This unique model requires the communication and trust of each of these disciplines with the head coach.

\section{Challenge}

eSport has not yet been recognised by the National Collegiate Athletic Association (NCAA) on college campuses, therefore they are not required to have physical clearance to participate, unlike other traditional NCAA athletes. They also do not require a 'return to play' clearance if an injury arises. This now empowers the coach, trainers and athletic directors as the individuals who may recognise the need to refer to health professionals. This proposed model focuses on colleges and high schools requiring eSport players who compete competitively on a varsity 
level should be required to have a physical examination to clear them for play.

\section{The proposed health model focuses on health and injury prevention}

Coaches of eSport teams should have a working knowledge of minimal health guidelines and signs of common overuse injuries as well as signs of gaming addiction. Physicians who screen these players should have a working knowledge of what gaming entails, the specific demands of the game or event as well as physical and emotional demands of the players.

The goal should be to have each player at least fulfil healthy lifestyle compliance with public health guidelines.

\section{Coach refers players to physical clearance}

- The head coach is the senior individual who trains the team and oversees, manages practices and provides game-specific training for the team.

\section{Typical evaluation of an athlete}

The model of eSport physical assessment is vastly different from the typical athlete evaluation model. Assessment should be designed to focus on all domains associated with this activity. There is no standardised assessment, and this evaluation is structured based on preliminary data:
- Sport physical—performed by the primary care sports medicine physician.

- Additional questions beyond the traditional sport physical examination.

- Ask focused questions regarding physical activity and nutrition.

- Evaluate social behaviour.

- Evaluate addictive behaviours.

- Inquire about academic performance.

- Inquire about musculoskeletal complaints.

- Evaluate vision.

\section{Assessment results and recommendations}

The primary care physician is the gatekeeper to recommend targeted treatment to the player and to the interdisciplinary team. Feedback on treatment and results should be provided back to the primary care doctor of this team as well as the coach.

The primary care physician's role is vital in assessing, identifying players' needs and referring the player to the right specialist for additional assessment and treatment. See figure 2 for the eSport team model, and table 1 for each professional's role in this model.

\section{CONCLUSIONS}

Overall, eSport players face challenges to master their gaming while addressing adverse repercussions on their health. Currently, the NCAA does not recognise eSport

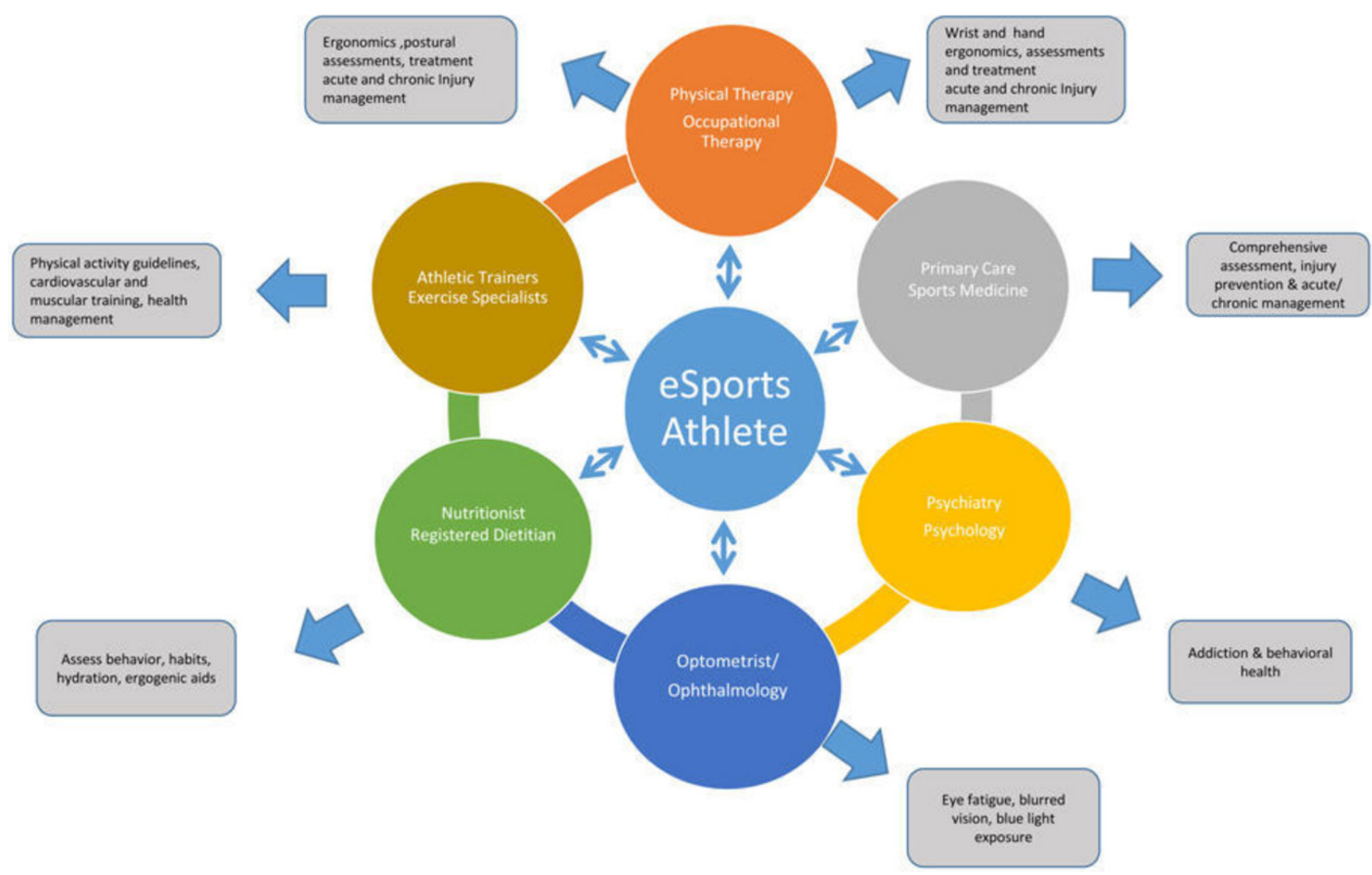

Figure 2 eSport health team model. 
Table 1 eSport management team roles

\begin{tabular}{|c|c|}
\hline Professional & Role \\
\hline \multirow[t]{3}{*}{ eSport athlete } & Report any symptoms of physical discomfort \\
\hline & $\begin{array}{l}\text { Be honest in the amount of game play and any addictive behaviours they may feel } \\
\text { they have }\end{array}$ \\
\hline & Be in good academic standing \\
\hline \multirow[t]{4}{*}{ Team physician } & Oversee all healthcare of the student -athlete \\
\hline & Inquire about academic performance \\
\hline & Inquire about musculoskeletal complaints \\
\hline & Evaluate vision \\
\hline Psychologist/psychiatrist & Perform assessments if suggested on addictive behaviour. \\
\hline Physical therapy/occupational therapy & $\begin{array}{l}\text { These specialists should be on referral from the team physician should hand, wrist, } \\
\text { neck or back pain arise. Ergonomic evaluation of playing position, strengthening } \\
\text { exercises, flexibility exercises. }\end{array}$ \\
\hline Ophthalmologist & $\begin{array}{l}\text { This specialist should be on referral to evaluate retinal damage, and photoreceptor } \\
\text { damage from excessive blue light exposure. Ophthalmologists have the ability to treat } \\
\text { retinal damage whereas an optometrist does not. }\end{array}$ \\
\hline Coach & $\begin{array}{l}\text { Assist in implementation of therapies and treatment, support the medical staff and } \\
\text { the protocol. }\end{array}$ \\
\hline
\end{tabular}

as a sanctioned sport therefore there are no management protocols for health or injury required for these teams yet. If a health professional finds a concern, it will be that individual's professional decision on return to play for these athletes. Being in good academic standing and managing injuries is the responsibility of individual institutions, players, coaches and trainers who interact with these players regularly. These players should be mandated by academic institutions and athletic departments to undergo a health evaluation annually to help prevent injury and to be screened for medical issues, similar to other traditional collegiate and high school sports.

\section{Special considerations, obstacles and advice}

- Coaches, athletic trainers and health professionals may be sceptical of acknowledging and acceptance of the new college 'athlete'. Be prepared for some distrust and resistance.

- Be prepared for resistance from eSport players. This is not a team that is usually required to do any physical activity and their days are usually spent gaming or doing school work. Scheduling times for evaluations may be difficult.

- Athletes may not report any conditions or lack of activity in order to minimise time away from gaming.

- Trust might be an issue with some teams. They are not used to the structure of medical teams. Most eSport players do not have an off season. Helping them understand that what you do is beneficial to them and may not improve their performance. Motivation might be difficult.

Acknowledgements The authors thank the NYIT eSport team for their contribution and insight in the development of the eSport questionnaire.

Contributors JDD planned and executed the study and was the primary writer and submitted the study. JB planned the study and assisted in editing the manuscript. GS helped plan the study, assisted in statistical analysis and editing the manuscript. HZ planned and executed the study with contributions to writing and editing.

Funding The authors have not declared a specific grant for this research from any funding agency in the public, commercial or not-for-profit sectors.

Disclaimer The results of this study are presented clearly, honestly, and without fabrication, falsification, or inappropriate data manipulation.

Competing interests None declared.

Patient consent for publication Not required.

Provenance and peer review Not commissioned; internally peer reviewed.

Open access This is an open access article distributed in accordance with the Creative Commons Attribution Non Commercial (CC BY-NC 4.0) license, which permits others to distribute, remix, adapt, build upon this work non-commercially, and license their derivative works on different terms, provided the original work is properly cited, appropriate credit is given, any changes made indicated, and the use is non-commercial. See: http://creativecommons.org/licenses/by-nc/4.0/.

\section{REFERENCES}

1. Buijsman $M, 2018$. Rainbow six: siege esports hours on twitch quadrupled compared to last year. Available from: https://newzoo. 
com/insights/articles/rainbow-six-siege-esports-hours-on-twitchquadrupled-compared-to-last-year/ [Accessed 13 Nov 2018].

2. Schwartz N, 2014. More people watch eSports than watch the World Series or NBA Finals. Available from: https://ftw.usatoday.com/2014/ 05/league-of-legends-popularity-world-series-nba [Accessed $17 \mathrm{Sep}$ 2018].

3. Hester B, 2016. Teens spend 25 times more of their time playing video games than going to the movies. Available from: http://www. ign.com/articles/2016/12/21/teens-spend-25-times-more-of-theirtime-playing-video-games-than-going-to-the-movies [Accessed 17 Sep 2018].

4. Townley S, Townley A, 2018. eSport: everything to play for. Available from: http://www.wipo.int/wipo_magazine/en/2018/01/article_0004. html [Accessed 17 Sep 2018].

5. Kane D, Spradley BD. Recognizing ESports as a Sport: United States Sports Academy. 19, 2017.

6. Talks TEDx, Melcher K, 2016. Gamers: the rising stars of collegiate athletics. Available from: https://www.youtube.com/watch?v= kcX11m1g3hs [Accessed 18 Sep 2018].

7. Sorokanich B, 2014. South korean university now accepts gamers as student athletes. Available from: https://gizmodo.com/southkorean-university-now-accepts-gamers-as-student-a-1547111361 [Accessed 17 Sep 2018].

8. AACRAO, 2018. Video gaming: the newest College sport. Available: https://www.aacrao.org/resources/newsletters-blogs/aacraoconnect/article/video-gaming-the-newest-college-sport [Accessed 19 Sep 2018].

9. Fogek S, 2018. High School Esports Competitions to Begin in U.S. Available from: https://variety.com/2018/gaming/news/high-schoolesports-1202758438/ [Accessed 18 Sep 2018].
10. Brautigam T, 2016. Esports needs to face its injury problem. Available from: https://esportsobserver.com/esports-needs-faceinjury-problem/ [Accessed 18 Sep 2018].

11. Thachil J. Deep vein thrombosis. Hematology 2014:19:309-10.

12. Lewis JM, Trinh P, Kirsh D. A corpus analysis of strategy video game play in Starcraft: Brood War. Proceedings of the 33rd annual conference of the cognitive science society, 2011.

13. Lejacq $Y, 2014$. How fast is fast? Some gamers make 10 moves per second. Available from: https://www.nbcnews.com/technolog/howfast-fast-some-pro-gamers-make-10-moves-second-8C11422946 [Accessed 18 Sep 2018]

14. Tosini G, Ferguson I, Tsubota K. Effects of blue light on the circadian system and eye physiology. Mol Vis 2016;22:61-72.

15. van der Lely S, Frey S, Garbazza C, et al. Blue blocker glasses as a countermeasure for alerting effects of evening light-emitting diode screen exposure in male teenagers. $J$ Adolesc Health 2015;56:113-9.

16. Burgess HJ, Fogg LF. Individual differences in the amount and timing of salivary melatonin secretion. PLOS One 2008;3:e3055.

17. Worsley PR, Rebolledo D, Webb S, et al. Monitoring the biomechanical and physiological effects of postural changes during leisure chair sitting. J Tissue Viability 2018;27:16-22.

18. Faigenbaum AD, Chu DA, Paterno MV, et al. Responding to exercise-deficit disorder in youth: integrating wellness care into pediatric physical therapy. Pediatr Phys Ther 2013;25:2-6.

19. Walker G, Faigenbaum AD, Avery D. Physical inactivity in youth: can exercise deficit disorder alter the way we view preventive care? ACSMs Health Fit J 2018;22:42.

20. WHO, 2018. Gaming disorder. Available from: http://www.who.int/ features/qa/gaming-disorder/en/ [Accessed 18 Sep 2018]. 